\title{
What academic publishing can do for science?*
}

\author{
Professor Dr. J.J. (Jos) Engelen \\ Chairman of the Governing Board of the Netherlands Organisation for Scientific Research, NWO, \\ The Hague
}

Ladies and Gentlemen, it is an honor and a pleasure for me to address you today on the subject of scientific publishing. 'What can academic publishing - and academic publishers - do for science?': that is my subject today. Scientific publishing is an absolutely essential part of scientific research; not just because scientific publications are a record of what has been achieved, but also - and even more importantly - because these publications are a source of knowledge for new researchers and therefore indispensable for the advancement of science.

Let me say from the outset: I consider the business of publishing to be a professional activity that requires specific expertise. In particular, the 'quality assurance' and 'quality control' of publications should be guaranteed by means of a well defined and transparent process. I will return to this subject later.

In addition, academic publishers are of course also essential for enabling access to results and for facilitating the creative use of these results - for allowing others to 'discover' them. This will be of growing importance, because we have not yet begun to fully exploit the possibilities offered by modern ICT.

Quality assurance and quality control. Allow me to entertain you with a short anecdote. Last December, an article was published in 'Science' that drew quite a bit of attention. The title was: 'A bacterium that can grow by using arsenic instead of phosphorus'. Quite spectacular: a new element had been added to the traditional six elements that are known to be the building blocks of life! In fact I read about this publication in a regular newspaper. My research institute in Amsterdam, Nikhef, has a subscription to the 'electronic' version of Science. But to my disappointment, I could not access the paper, because it had been published in Science Express and my research institute had not paid the additional fee of $\$ 825$ that would have granted me access to the publication. Obviously, for the publisher of Science Magazine and Science Express, scientific papers are a commercial business: you pay extra for really 'hot' papers, but is this not going too far? What value was added by the publisher that would justify this additional fee? I cannot think of any. Perhaps it was explained by the exceptional quality and relevance of this paper? Certainly not in this case, as it turned out that the claim made by the authors in the title was not substantiated in the paper. The scientific community considered this a bad paper, premature at best.

Let me add a second anecdote. Last century - in the nineteen seventies - when I wrote my PhD thesis, one of the chapters was based on an article that I had published in a journal called 'Nuclear Physics B'. In return for having the paper reviewed and published, I had given away the copyright, as was customary.

\footnotetext{
*Keynote speech APE 2011.
} 
I was advised to ask permission from the publisher before reproducing the paper in my thesis. Let me give you the title of this paper: 'A study of non-charge-exchange $\mathrm{K}^{0}(\mathrm{bar}) \pi^{-}$production in the reaction $\mathrm{K}^{-} \mathrm{p} \rightarrow \mathrm{K}^{0}$ (bar) $\pi^{-} \mathrm{p}$ at $4.2 \mathrm{GeV} / \mathrm{c}^{\prime}$. Not as spectacular as the previous title, but still: I asked permission and of course it was granted. Now, why did I do that? Not because I was legally obliged to. In those days I couldn't care less... No, it was because an external party had put a value on my research and on my results, and because it had, independently, assured the quality of my results. Asking and getting the permission was a reaffirmation of all this, and this made me feel proud. It was important to me as a young scientist.

And that, ladies and gentlemen, is the essence of scientific publishing: the quality of the research and the results that are published should be guaranteed. This is usually done under the supervision of an editor-in-chief and an editorial board, with the help of a well organized peer review system. Although this is perfectly obvious to this audience, its importance cannot be overstated. For scientific publishing, all other considerations, and certainly those of a commercial nature, should be secondary to those of quality.

You might be thinking: why ask permission to reproduce an article you wrote yourself? Or even more in general: why pay a subscription fee to get access to articles that are based on publicly funded research? Should these articles not be in the public domain? Yes, I think they should. But I am aware that these articles cannot be made available for free. Publishing is not for amateurs and volunteers. The role of professional academic publishers has been absolutely central to creating and developing the top quality journals that we have and need. However, the 'business model' for scientific publishing should be changed - from 'subscription fee based' to 'author pays'. This is the best way to optimize the flow of knowledge. Changing the business model is straightforward in principle. The cost of publishing, including peer reviewing, distribution, archiving etcetera should be determined and agreed. It could be expressed, for example, as a cost per page, or a cost per article. This cost should then be borne by the research grant of the author or authors. This operation is cost neutral for the public funds involved: they merely shift from 'library budget' to 'research budget'. This is proving to be as hard in practice as it is simple in principle. Why is this so?

Firstly and primarily, because the established publishers are not automatically motivated to change their business model. Some are willing to look into it, but certainly not all of them. I can understand this: why change a profitable business model? It is somewhat harder to understand why non-profit organizations in the publishing business should be reluctant to change. For example, the American Association for the Advancement of Science: publisher of Science Magazine and Science Express.

I am addressing you as a scientist and as the president of a national organization dedicated to funding research. What can we do, what can the scientific community do, to promote and accelerate the transition to open access publishing? Because that is what I am discussing here. I believe that what academic publishing can do for science is to adopt open access - while continuing to give the quality assurance mentioned earlier - and deploy technologies to improve access and 'discovery'.

Open access publishing has been made much easier by the advent of the World Wide Web. In principle, of course, the open access model is independent of the technology, but in practice it has received an enormous boost through the availability of 'web based' publishing. So again, what can we do to accelerate the transition to open access publishing? Obviously we will have to accept that, during a transitional period, both publishing models - the classical one and the open access one - will coexist for a while. In my opinion, the organizations funding research should start to provide authors with funds for publication, while at the same time the libraries still pay subscription fees. For a while. In the field of Particle Physics, for instance, the so-called SCOAP3 consortium has successfully organized a large 
number of funding agencies, labs and libraries in a concerted effort to promote open access publishing in high energy physics.

My own organization, the Netherlands Organisation for Scientific Research, makes funds available for publications according to the 'author pays' (or 'consortium pays') model. But the number of eligible journals, across all fields of science, is still rather limited, and although the NWO fund is used, it has not been swamped by applications. A recent, rather large-scale, survey by a project called SOAP set out to discover what scientists felt was the main barrier to open access publishing. The fact is that $90 \%$ of scientists surveyed (more than 40,000 answered the survey) think that open access is beneficial, but only $8-10 \%$ of their articles are currently published open access. Asked why they do not publish open access, $40 \%$ of scientists say the problem is funding and $30 \%$ say it is quality.

There are examples of successful open access initiatives. BioMed Central and PLoS started open access journals which have reached a very high quality standard, and often even in fields where there were no journals - or at least no high-quality journals. This makes a virtuous circle: there are good journals: scientists aspire to publish there, making them even better. Schemes like NWO's allow fees to be met, and the journals can thrive.

In the applications of researchers to the NWO Incentive Fund for Open Access, PLoS and Biomed Central are mentioned most often. But - to be fair - many other titles are also mentioned. I consider that very promising. A couple of examples are: the journals Atmospheric Chemistry and Physics and Climates of the Past.

It seems to me that an ideal way forward would be, first, the conversion of existing and well established journals to the new model: open access. The journals of commercial and 'not for profit' publishers alike. Some publishers, by the way, have made commendable steps towards open access by offering it as a choice alongside the classical model. And although these steps are much appreciated, to my mind they do not go far enough.

Second, if the conversion of existing, high quality journals remains insufficiently successful, steps should be taken to start more new journals according to the open access model. Examples in the humanities can be given by NWO in February 2011, after a pilot round has finished assessing about twenty applications for new open access journals in the humanities. Setting up a new journal from scratch is not a venture to be undertaken lightly. It is a full time occupation for a number of persons and if these are initially 'volunteers', at a certain point the new journal will have to be run by a professional staff, embedded in a professional organization if it is to be a sustainable venture.

In order to help initiatives for starting new open access journals, my organization, NWO, also makes funds available to support such initiatives through the initial phase. After an initial period, these journals should of course be able to stand on their own feet. Although setting up a new journal is difficult enough, there is another hurdle to overcome for such a journal to survive, a hurdle of our own making. If I say 'our own making' I mean us: the scientific community, the funding organizations. And the hurdle I refer to is the so called impact factor. This impact factor is a measure of the quality, of the importance of a journal: as you know it measures the average number of citations the journal receives per published article. In judging the past performance of researchers, and in assessing the potential of their grant applications, their publications, and the impact factors of the journals those publications appeared in, are taken into account. The impact factor of any new journal - and so also of new open access journals -, is by definition zero. Therefore, scientists are reluctant to submit their articles to journals that are not yet established. In order to break out of this vicious circle we should use our imagination. I myself have appealed to senior researchers in the Netherlands with an established high reputation, to set an example and submit their work to open access journals, even if the impact factor of these journals is not 
yet high. With their help this impact factor would certainly grow in no time. I do not, however, labor under the delusion that my appeal will receive a massive positive response. Therefore, I would like to make another suggestion. Why don't we assign an initial, 'artificial' impact factor to new open access journals. This impact factor could be based on the impact factor of journals covering a similar field, with similar editorial criteria etcetera. It could be based on the reputation of the members of the editorial board. After two or three years, this initial impact factor could then be replaced by the real one - even sooner should the real impact factor grow successfully. In any case, as I said earlier, NWO has made some funds available to help new initiatives through the initial phase, until they are self-supporting.

I know that for most scientists, open access publishing is not as important as publishing 'as such', i.e. in established journals with a good reputation. This is partly due to the impact factor that I just mentioned, but certainly also because scientists are not yet familiar with the subject. Therefore, I have recently suggested that scientific conferences include a session of a couple of hours on open access. An overview of the existing open access journals relevant for the specific field of that conference could be given and, if necessary or desirable, new initiatives could be started. NWO has announced that conferences can apply for funds in order to specifically finance the inclusion of a session on open access.

Although in this talk I mainly focus on open access publishing in scientific journals, the issue is equally relevant for books. Open access for academic books (or monographs) is a relatively new idea. Access to books is currently fragmented and limited. Books are not widely available online and the average circulation of printed books has dropped considerably over the past decades. The sustainability of traditional monograph publishing is under threat, and there are a number of initiatives, such as OAPEN (Open Access in European Networks) here in Europe - to develop an open access model for books.

With this in mind, we decided to include monographs in our open access policy. NWO established an incentive fund for both open access journal articles and open access books resulting from NWO projects. Besides, we are also taking part in a pilot project with OAPEN to fund fifty open access books in the next two years, in order to gain experience with this new form of book publishing and collect data on the effects of open access on the impact of books.

What are the reasons for the scientific community, including the funding organizations, to insist so strongly on the importance of open access publishing? There are several. There are reasons of cost. Let me repeat that we realize this cost cannot be reduced to zero, that is not realistic and that is not the intention of my plea. Scientific publishing is not just putting your articles on the web, I stated that earlier. Yet, in the 'author pays' model, it is certainly easier to control costs and, indeed, some subscription fees have risen to astronomical heights during the last decade or so. Let me illustrate this by a third (and last!) anecdote. A few days ago I had a meeting with the research director of a medium sized company which specializes in producing and improving plant seeds. This company is successful in providing high quality and innovative products and maintains a large R\&D department. In fact the company spends $15 \%$ of its turnover on R\&D. The researchers have a lively interest in the scientific literature in their field. But the company noticed that the subscription fees for a significantly large spectrum of journals have become uncomfortably high. The company applied to join the collective contract that Dutch universities have with the publishers, but the publishers turned them down. But now the company has found the solution: a few of their R\&D workers have enrolled at a university, and in this way they, and through them their colleagues of course, have access to the university libraries and subscriptions. In a knowledge based economy knowledge should flow freely!

Aside from reasons of cost, we have another reason for supporting open access: the advancement of science itself. A comprehensive, quality-controlled body of scientific results, combined with new 
web-based search tools, should allow researchers to advance knowledge across the world and across disciplinary boundaries. There is great potential for innovative tools here: humans cannot read 1.5 million articles per year, machines can.

Ladies and gentlemen, it is time for me to conclude. An important underlying theme of my talk this morning was that scientific research is a necessary ingredient for a knowledge-based society, which includes a knowledge-based economy and its growth. A professional publication process is indispensable for the dissemination of knowledge and the advancement of knowledge through further, innovative scientific research. These goals of scientific publishing are best reached by means of an open access publishing business model. In my judgment it is essential that open access becomes the standard and does not remain the exception. Open access publishing should become a requirement for publicly funded research. In order to make open access publishing a success, the enthusiastic cooperation of the professional publishing companies active on the scientific market is highly desirable.

I would like to conclude by stating my firm conviction that open access publishing will be the future standard - sooner or later!

Thank you for your attention. 